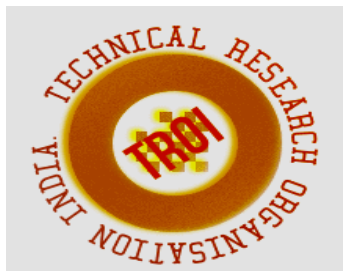

\title{
RATIONAL DESIGN METHODOLOGY FOR DESIGN OF UNDERGROUND CAVERNS, A CASE STUDY
}

\author{
${ }^{1}$ Syed Ariff, ${ }^{2}$ john gladious ${ }^{3}$ vikram $P$ \\ ${ }^{1}$ Principal \& Prof Dept of Mining Engg Dr T.T.I.T KGF \\ ${ }^{2}$ Associate prof Dept of mining Engg Dr TTIT,KGF \\ ${ }^{3}$ Asst Prof Dept of mining Engg, Dr TTIT,KGF
}

\section{ABSTRACT}

Discontinuum modeling Universal Discrete Element Code ( UDEC ) to study the rock mass response due to excavation and its long term stability analysis is used world wide. It is important to calibrate and ascertain the computed values by modeling with the monitoring of the excavations using instrumentations. The instrumentation using Magnetic ring multi point bore hole extensometers ( MRMPBX ) is used for monitoring the deformation of walls of the Sardar Sarovar Powerhouse.

To calibrate the numerical model and to assess the long term stability of the excavations, extensometers were installed in the upstream and downstream walls of the powerhouse cavern. The locations of the instruments were selected based on the results of numerical modeling, where the maximum deformations are expected. The results of instrumentation and numerical modeling are compared. The computed displacements compare well with those observed through instrumentation.

Keywords: Stress Analysis, Extensometers, Micrometer, End Anchor, Zero Position

\section{INTRODUCTION}

Stress analysis is being carried out using discontinuum modeling to study the rock mass response due to excavation of the powerhouse. In order to calibrate the numerical model, it was proposed to investigate the rock mass behavior through instrumentation. The present instrumentation was installed after the powerhouse was excavated.

\section{OBJECTIVE}

The objective of this investigation is to install instruments to study,

1. The deformations of the walls and,

2. Assess the long term stability of the powerhouse

3. Compare the results with those of numerical modeling.

\section{INSTALLATION OF THE INSTRUMENTS}

The locations for installation of the instruments were selected based on the results of numerical modeling, where the maximum deformations are expected. Out of these twelve instruments, six of them were installed during first week of February and two of them were installed during June $12-14$. Rests of the extensometers were installed during November 2000. Six to nine anchors were installed in each of the boreholes depending on the availability of depth of drill holes.

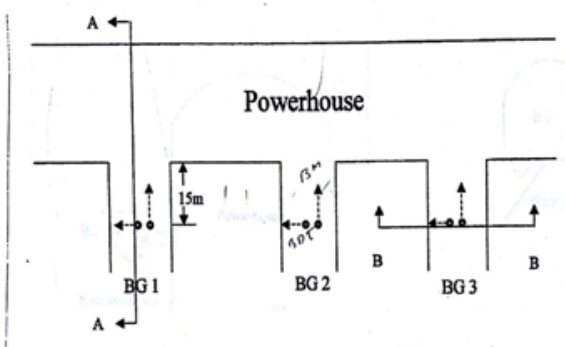

Fig1Schematic diagram of the power house showing location of extensometer in busgallery plan view 


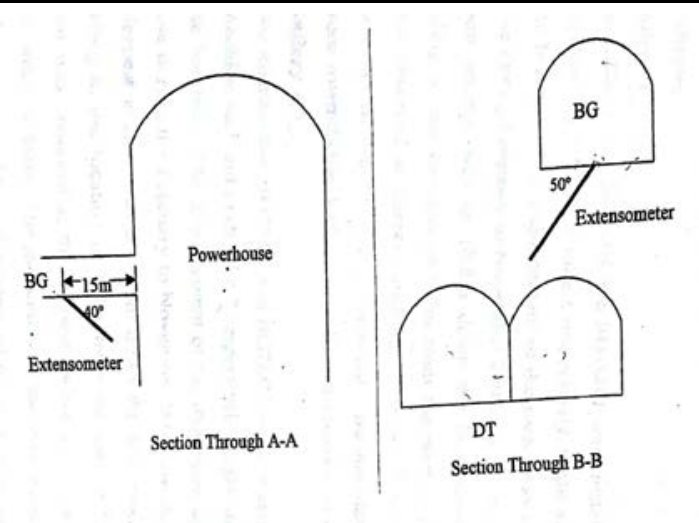

\section{Schematic diagram of the power house showing location of extensometer in bus- gallery section view}

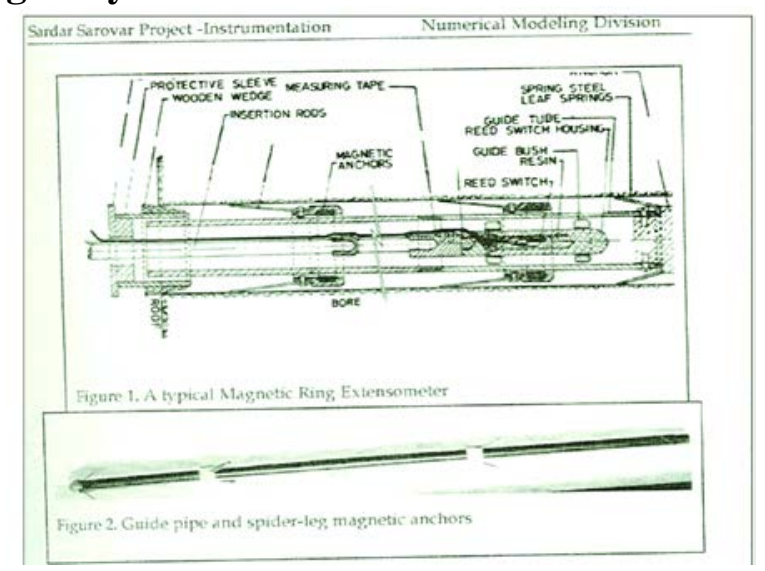

\section{Extensometers and anchors}

A typical magnetic ring extensometer is shown in Figure 1. The installation of the extensometer is as follows. The guide pipe with end anchor ( non-magnetic) shown in Figure 2 will be inserted first. The magnetic anchors are pushed over the guide pipe to the desired location. The end pipe and plate is securely fixed to the wall and grouted. To measure the position of an anchor, the probe is inserted through the micrometer fitted to the end pipe. When the probe cuts the magnetic field of the anchor, an electric circuits will be closed a light switch will glow. The position of the anchor is noted from the main scale and micrometer reading.

\section{METHOD OF OBSERVATIONS}

At the time of installation of multipoint borehole extensometers in February 2000, the procedure of taking readings using micrometer head is as follows. To begin with, the original reading of main scale say at $5 \mathrm{~cm}(50 \mathrm{~mm})$ of the main scale, should coincide with the zero of the micrometer head. The probe along with the graduated scale should then be inserted in the PVC pipe and the position of the first magnetic ring was approximately located. Once the position of the ring is located, the probe along the graduated scale is pulled back by about 5$8 \mathrm{~mm}$ until the light is extinguished. The $\mathrm{cm}$ scale is then clamped with the micrometer head at $\mathrm{cm}$ marking and the head is rotated thereby inserting the scale inside the pipe.. The micrometer head is slowly rotated clockwise. As soon as the probe enters the magnetic field of the ring, the light of the readout unit will glow. The reading on the micrometer head is noted and added to main scale reading to get the exact location of the ring from the zero position of the micrometer head. This is repeated 3 to 5 times and the average value is recorded. This procedure is repeated for the subsequent sets of observations.

\section{DATA ANALYSIS}

Periodically, the readings were taken once in a month starting from February 2000 to March 2001. The displacements were observed at different depths from the surface of the wall. The observed and the computed surface movements values of the power house walls in mm have been listed in the Table 1 The positive values of the deformations indicate the rock mass movement is towards the excavation. It has been observed that the deformations were stabilized over a period of time.

\section{Summary and Conclusions}

To calibrate the numerical model and to assess the long term stability of the excavations, extensometers were installed in the upstream and downstream walls of the powerhouse cavern. The locations of the instruments were selected based on the results of numerical modeling, where the maximum deformations are expected. The results of instrumentation and numerical modeling are shown in table below. The column 2 indicates the computed deformation. The column 3 indicates the observed deformations. The computed displacements compare well with those observed through instrumentation. 
Table - 1

Observed and Computed surface movements of the Powerhouse walls in $\mathbf{m m}$

\begin{tabular}{|l|l|l|}
\hline \multirow{2}{*}{ Location } & \multicolumn{2}{|c|}{ Displacements } \\
\cline { 2 - 3 } & Computed & Observed \\
\hline CH 1595 D/S & 10.91 ( EL 10) & 8.0 ( EL 7) \\
\hline CH 1540 D/S & 12.03 ( EL 10 ) & 11 ( EL 7) \\
\hline CH 1515, EL 0 D/S & 11.54 & 20 \\
\hline CH 1515, EL 10 D/S & 22.14 & $8.0^{*}$ \\
\hline CH 1515, EL 20 D/S & 12.13 & $6.0 *$ \\
\hline CH 1545, EL 0 U/S & 11.72 & 14.0 \\
\hline
\end{tabular}

* These extensometers were installed after 6 months of start of ramp excavation.

\section{REFERENCES}

1. Stress Analysis of Underground Powerhouse Cavern of Sardar Sarovar Project - Dr. R. Venugopala Rao , N I R M. K.G.F. March 2000
2. Geotechnical instrumentation and monitoring in open pit and underground mining / Kalygoorlie/ Western Australia/ 21- 23 June 1993 by T. Szwedzicki Publishers - A.A. Balkema / Rotterdam/ Brook field/ 1993. 